\title{
Cartilage Expression of a Type II Collagen Mutation in an Inherited Form of Osteoarthritis Associated with a Mild Chondrodysplasia
}

\author{
David R. Eyre, "* Mary Ann Weis," and Roland W. Moskowitz \\ Departments of *Orthopaedics and ${ }^{\ddagger}$ Biochemistry, University of Washington, Seattle, Washington 98195; \\ and ${ }^{8}$ Department of Medicine, Case Western Reserve University, Cleveland, Ohio 44106
}

\begin{abstract}
In a family who expressed severe dominantly inherited osteoarthritis, the underlying mutation was traced by genomic sequencing to a single base change which predicts an amino acid substitution of cysteine for arginine at residue 519 of the triple-helical domain of the type II collagen molecule (AlaKokko, L., C. T. Baldwin, R. W. Moskowitz, and D. J. Prockop. 1990. Proc. Natl. Acad. Sci. USA. 87:6565-6568). In the present study we examined whether this predicted protein phenotype was evident in articular cartilage obtained from an affected family member who underwent hip surgery. The cartilage collagen was solubilized by $\mathrm{CNBr}$ digestion. Cysteine residues were labeled by reduction and alkylation with ${ }^{14} \mathrm{C}$-iodoacetate. Collagen CNBr-peptides were fractionated by ion exchange and reverse phase column chromatography. One peptide from the $\alpha 1$ (II) chain, $\alpha 1$ (II) $\mathrm{CB8}$, was found to be radiolabeled. Tryptic peptides were prepared from it and identified by microsequence analysis. The results show that approximately one-quarter of the $\alpha$ I(II) chains present in the polymeric extracellular collagen of the patient's cartilage contained the Arg $_{519}$-to-Cys substitution. The protein exhibited other abnormal properties including disulfide-bonded $\alpha 1$ (II)-dimers and signs of posttranslational overmodification. The premature cartilage failure and osteoarthritis are presumably a result of the abnormal type II collagen being expressed in the cartilage matrix. (J. Clin. Invest. 1991. 87:357-361.) Key words: articular cartilage $\bullet$ chondrodystrophy $\bullet$ genetic disease $\bullet$ osteoarthrosis $\bullet$ protein sequencing
\end{abstract}

\section{Introduction}

Osteoarthritis (OA) ${ }^{1}$ is the most common disease of joints. Though of diverse etiology and poorly understood pathogenesis, its cardinal feature is a progressive disruption and erosion of articular cartilage (1). Articular cartilage consists mostly of

Address reprint requests to Dr. David R. Eyre, Orthopaedic Research Labs, RK = 10, University of Washington, Seattle, WA 98195 .

Received for publication 23 August 1990.

1. Abbreviations used in this paper: OA, osteoarthritis; PTH, phenylthiohydantoin.

J. Clin. Invest.

(c) The American Society for Clinical Investigation, Inc.

0021-9738/91/01/0357/05 \$2.00

Volume 87, January 1991, 357-361 an extracellular matrix that is essentially a collagen fibril network filled with highly hydrated proteoglycans (2). The collagen network is a covalent polymer of type II collagen molecules (each molecule a homotrimer, $[\alpha 1(\mathrm{II})]_{3}$, that normally lacks any cysteine residues), in association with two other cartilagespecific collagens, types IX and XI, in small amounts (3). In adult cartilage, chondrocytes continue to synthesize and replace proteoglycans but turn over the collagen slowly (4) so that most of its fabric must function for life.

Various forms of familial generalized OA have been described $(5,6)$. In three unrelated families who expressed severe dominantly inherited osteoarthritis, linkage studies showed that the condition was coinherited with an allele of the collagen type II gene (COL2A1) $(7,8)$. The patient in the present study, G.J. (age 46 at time of left total hip replacement), and other affected family members experienced joint symptoms in their second and third decades, which progressed into typical clinical and radiographic evidence of generalized OA $(8,9)$. Although the affected family members had mild spinal chondrodysplasia, their precocious OA developed in peripheral joints that lacked epiphyseal deformities or other evidence of chondrodysplasia. The recent demonstration that the dominantly inherited disease symptoms were cotransmitted with a mutant COL2A 1 allele that predicts an $\mathrm{Arg}_{519}$-to-Cys substitution (10) implies that the disease is a direct result of abnormally expressed type II collagen in joint cartilage. With the availability of surgical tissue, this prediction was tested by protein analysis of the collagen from the cartilage matrix. The results confirm the expression of the mutant protein and imply that the osteoarthritis is a consequence of the collagen molecular abnormality in the cartilage.

\section{Methods}

Articular cartilage was sampled from relatively intact surfaces on the surgically removed femoral head and stored frozen at $-70^{\circ} \mathrm{C}$. Areas of severe erosion and potential fibrocartilaginous repair were avoided.

Preparation and chromatography of CNBr-peptides and tryptic peptides. A portion of cartilage ( $40 \mathrm{mg}$ dry $\mathrm{wt}$ ) from the least pathologically involved surfaces on the femoral head was digested with $\mathrm{CNBr}$ in $70 \%$ (vol/vol) formic acid (11). The digest was reduced with dithiothreitol and alkylated with ${ }^{14} \mathrm{C}$-iodoacetic acid to convert cysteines to ${ }^{14} \mathrm{C}$-carboxymethylcysteine (12) and so provide a marker for the mutant peptide. Collagen CNBr-peptides were fractionated by sequential cationexchange (Mono-S HR 5/5; Pharmacia Fine Chemicals, Piscataway, $\mathrm{NJ})$ and reverse phase $(\mathrm{C} 8,25 \mathrm{~cm} \times 4.6 \mathrm{~mm}$, model RP-300; Brownlee Labs, Santa Clara, CA) HPLC $(13,14)$. Fractions encompassing ${ }^{14} \mathrm{C}$-labeled and unlabeled $\alpha 1$ (II)CB8 (identified by liquid scintillation counting and SDS-PAGE), were pooled and digested with trypsin (sequenc- 
ing grade; Boehringer Mannheim Biochemicals, Indianapolis, IN). Tryptic peptides were separated by reverse phase HPLC (Brownlee Labs RP-300) using a gradient ( $0-30 \%$ in $60 \mathrm{~min})$ of acetonitrile: $n$-propanol $(3: 1 \mathrm{vol} / \mathrm{vol})$ in $0.1 \%$ (vol/vol) of trifluoracetic acid at $1 \mathrm{ml} / \mathrm{min}$ (14). Peptide yields were compared by the areas under their UV absorbance peaks and the recoveries of PTH-amino acids on sequence analysis.

Pepsin-solubilized collagen. Another portion ( $40 \mathrm{mg}$ dry wt) of the finely diced tissue from the most intact surfaces on the femoral head was extracted in $4 \mathrm{M}$ guanidine $\mathrm{HCl}, 0.05 \mathrm{M}$ Tris $/ \mathrm{HCl}, \mathrm{pH} 7.0$ at $4^{\circ} \mathrm{C}$ for $48 \mathrm{~h}$. The washed residue was digested with pepsin and solubilized collagen type II molecules were isolated by differential precipitation with $\mathrm{NaCl}$ as described (15). Collagen from normal human articular cartilage from a male, age 25 , was prepared similarly as a control. A portion of the patient's isolated type II collagen was reduced and alkylated with ${ }^{14} \mathrm{C}$-iodoacetate. SDS-PAGE was carried out by the method of Laemmli (16) in 6 and $12.5 \%$ polyacrylamide gels.

Protein microsequencing. Edman sequencing of individual tryptic peptides was carried out on a Porton 2090E machine equipped with on-line HPLC analysis of phenylthiohydantoin PTH amino acids using the manufacturer's standard program.

\section{Results}

The ${ }^{14} \mathrm{C}$-iodoacetate-treated $\mathrm{CNBr}$-digest of the patient's cartilage gave one major ${ }^{14} \mathrm{C}$-labeled component on cation exchange HPLC (Fig. $1 a$ ). The fractions marked by the bar were shown by SDS-PAGE to encompass the peptide $\alpha$ l(II)CB8, and were pooled for reverse phase HPLC (Fig. $1 b$ ). Similarly, the pool of further purified $\alpha 1$ (II)CB8 (indicated by bar in Fig. $1 \mathrm{~b}$ ) was dried for trypsin digestion. The columns used for the chromatograms in Fig. 1, $a$ and $b$, were calibrated with type II collagen $\mathrm{CNBr}$-peptides from normal human cartilage. In Fig. $1 a$, the peak eluting between fractions 25 and 35 is $\alpha 1$ (II)CB 10 and between fractions 40 and 50 is $\alpha 1$ (II)CB11; radiolabeled $\alpha 1$ (II)CB8 eluted slightly earlier than unlabeled $\alpha 1$ (II)CB8, hence the broad pool of fractions taken for further analysis.

Fig. 2 shows the results of SDS-PAGE and autoradiography which confirmed a concentration of ${ }^{14} \mathrm{C}$-activity in peptide
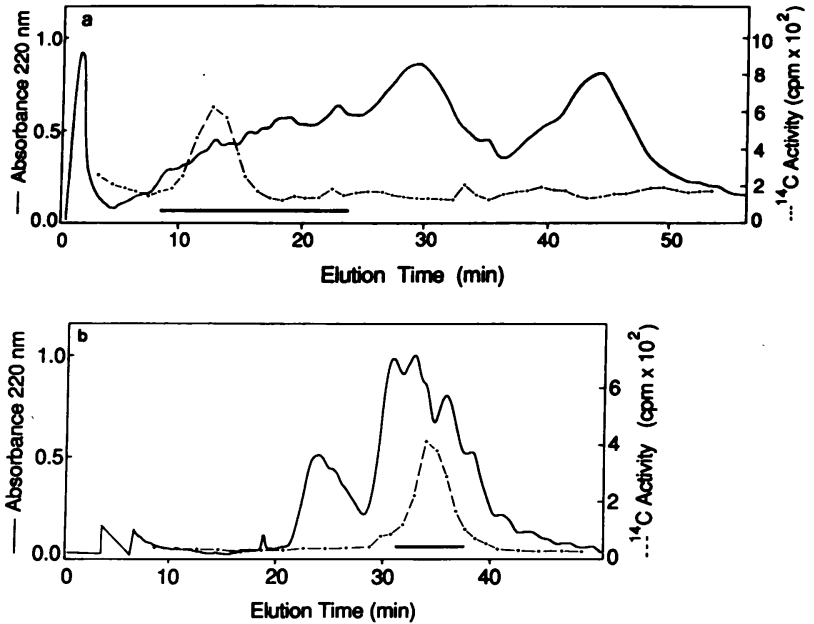

Figure 1. Cyanogen bromide peptides from type II collagen of the patient's cartilage fractionated by HPLC. Cysteine residues in the cartilage digest were labeled by reduction and alkylation with ${ }^{14} \mathrm{C}$ iodoacetate before chromatography. (a) Cation-exchange HPLC of the digest on a column (mono-S HR5/5; Pharmacia Fine Chemicals) eluted with a linear gradient of $0.07-0.26 \mathrm{M} \mathrm{NaCl}$ in $0.02 \mathrm{M} \mathrm{Na}$ formate, $10 \%$ (vol/vol) acetonitrile, $\mathrm{pH} \mathrm{3.8,} \mathrm{over} 70 \mathrm{~min}$ at $1 \mathrm{ml} / \mathrm{min}$. Solid line shows the profile of absorbance at $220 \mathrm{~nm}$ of total peptides in the digest. The dotted line is the profile of ${ }^{14} \mathrm{C}$-activity showing one major component. The fractions marked by the bar were pooled for reverse phase HPLC. (b) Reverse phase HPLC on a C-8 column (25 $\mathrm{cm} \times 4.6 \mathrm{~mm}$, Brownlee Labs RP300) eluted with a complex gradient $(5-20 \%$ in $50 \mathrm{~min})$ of acetonitrile: $n$-propanol (3:1 vol/vol) in $0.1 \%$ (vol/vol) trifluoroacetic acid at $1 \mathrm{ml} / \mathrm{min}$. The fractions marked by the bar in $b$ were pooled for trypsin digestion.

$\alpha 1$ (II)CB8 in the CNBr-digest of the patient's cartilage. Sequential gel lanes are shown for those fractions that span the region of the chromatogram where $\alpha 1$ (II)CB8 elutes on reverse phase HPLC of a sample of the total CNBr-digest of the pa- a

\section{Coomassie Stain}

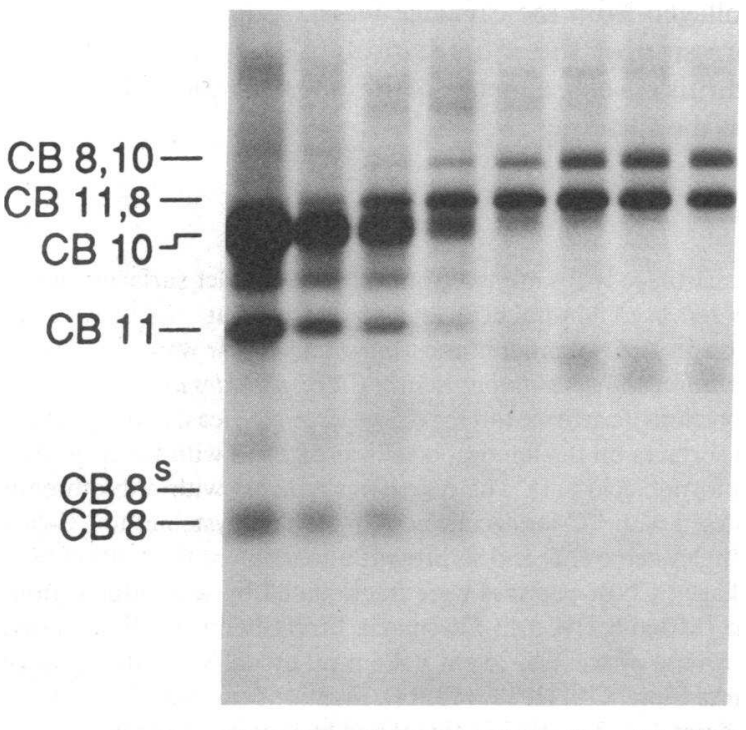

$\begin{array}{llllllll}35 & 36 & 37 & 38 & 39 & 40 & 41 & 42\end{array}$ b
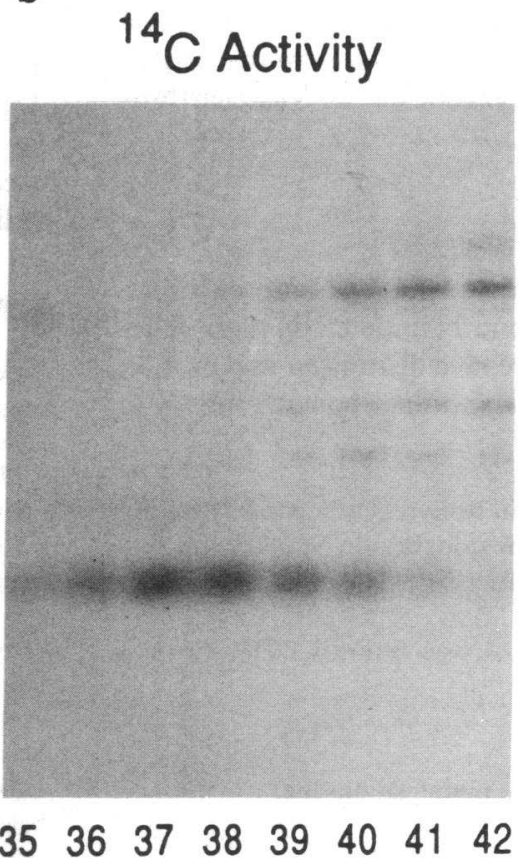

Figure 2. SDS-12.5\% polyacrylamide electrophoresis of fractions from reverse phase HPLC containing the ${ }^{14} \mathrm{C}$-labeled peptide $\alpha 1$ (II)CB8. A portion of the ${ }^{14} \mathrm{C}$-iodoacetate-treated CNBr-digest of whole cartilage was run directly on RP-HPLC (as in Fig. $1 b$ ). Fractions (1 ml) were collected, dried, and run in individual gel lanes. The elution position of $\alpha 1$ (II)CB8 was identified by protein staining (Coomassie blue, $a$ ); the ${ }^{14} \mathrm{C}$ labeled mutant form of $\alpha 1$ (II)CB8 8 (autoradiogram, $b$ ) had a slightly slower electrophoretic mobility and peaked a fraction or two later on RP-HPLC than normal $\alpha 1$ (II)CB8 in the same digest. Radiolabeled partial $\mathrm{CNBr}$ cleavage products containing $\alpha 1$ (II)CB8 (CB8, 10 and CB11, 8) were also evident in the autoradiogram. 


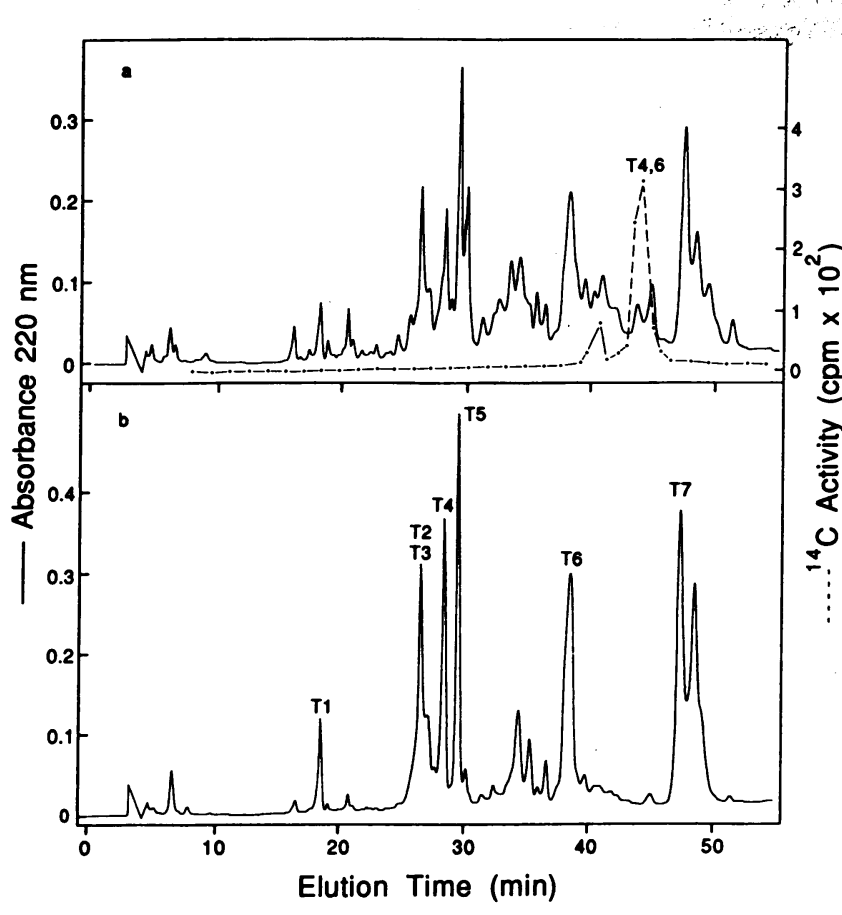

Figure 3. Tryptic peptides of the purified CNBr-fragment, $\alpha 1$ (II)CB8, fractionated by reverse phase HPLC from $(a)$ patient and $(b)$ human control (male, age 25) articular cartilage.

tient's cartilage. It can be seen that the mutant $\alpha$ l(II)CB $8^{8}$ peptide is slightly retarded on SDS-PAGE compared with its unlabeled normal counterpart, which could be a result of it being more overmodified posttranslationally or an effect of the carboxymethylcysteine residue replacing arginine.

Tryptic peptides from the $\alpha 1$ (II)CB 8 fragment were fractionated by reverse-phase HPLC (Fig. 3 ). The ${ }^{14} \mathrm{C}$ activity was recovered in a single peptide, T4,6 (Fig. $3 a$ ). This peptide, and several of the other tryptic fragments (T1-T7) of $\alpha 1$ (II)CB8 indicated as peaks in Fig. $3 b$, were identified by aminoterminal microsequencing. Fig. $3 a$ is more complex than Fig. $3 b$ because the CNBr-peptide fraction from the patient taken for trypsin digestion (see Fig. 1) was less pure than the control, to ensure a quantitative recovery of the total pool of mutant and normal $\alpha 1$ (II)CB8. The small peak of ${ }^{14} \mathrm{C}$-activity eluting at 41 min in Fig. $3 a$ appears to be a chromatographic variant of T4,6 since microsequencing gave the $T 4,6$ sequence including ${ }^{14} \mathrm{C}$ carboxymethylcysteine at cycle 12 ; the two peaks may represent homoserine and homoserine lactone-containing forms of the peptide (17).

Fig. 4 compares the results of microsequence analysis on peptide T4,6 with the known sequence of human $\alpha 1$ (II)CB8, and shows the identification of ${ }^{14} \mathrm{C}$-carboxymethylcysteine at cycle 12 (residue 519 of the human $\alpha$ (II) triple helical domain). In all, sequencing identified the first 42 amino acids of the 44-residue T4,6 peptide, identical to the cDNA-based sequence shown in Fig. $4 b$ except for $\mathrm{Cys}_{519}$. The yields of peptides T4 and T6 (which derive from the product of the patient's normal allele) relative to peptide T4,6 and to other peptides common to both alleles, indicated a ratio of mutant to normal $\alpha 1$ (II) chains in the patient's tissue of 1:3.

Collagen extracted from the patient's cartilage by pepsin showed a protein band by SDS-PAGE that was absent from extracts of control human cartilage and which disappeared

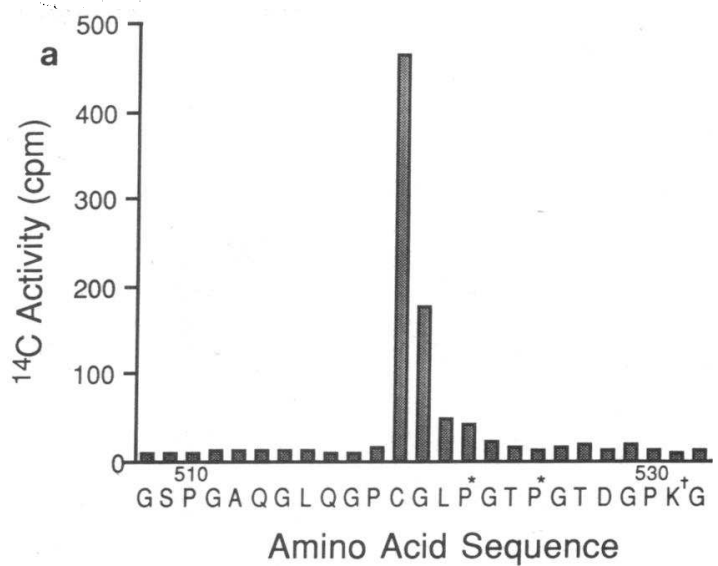

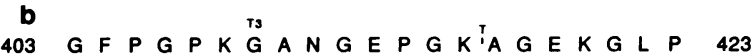

$424 G$ A P G L R'G L'P G K'D G E T G A A G ${ }^{T 5} P$ P 444

445 G P A $P$ A G E R 'G E Q A P G P S G $Q 465$

$466 G L P G P P G P P G{ }^{\prime 7} E G G K P G D Q G V P \quad 486$

487 G E A G A P G L V G P R 'G E R G F P $P^{\top 2} G E R^{i} 507$

508 G S P G A ${ }^{\top 4} Q G L Q G P C^{R} G L P G$ T P G T D 528

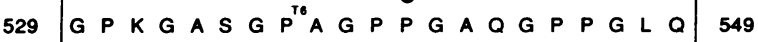

550 G M

Figure 4. Microsequencing results on the cysteine-containing tryptic peptide T4,6 isolated from the patient's cartilage collagen. $(a)$ The

${ }^{14} \mathrm{C}$-activity measured in a portion taken from each cycle of Edman degradation of peptide T4,6 (isolated as in Fig. $3 a$ ) is plotted as a bar graph against the first 25 residues of the amino acid sequence determined by on-line PTH-amino acid analysis. The results established that cycle 12 (residue 519) was carboxymethylcysteine alone. At cycle 24 (residue 531) no amino acid was detected consistent with it being a glycosylated hydroxylysine (indicated by $\mathrm{K}^{+}$). The single letter code for amino acids is used. $\mathrm{P}^{*}$, 4-hydroxyproline; $\mathrm{K}^{+}$, glycosylated hydroxylysine. (b) The complete amino acid sequence of residues 403-551 (peptide $\alpha 1$ (II)CB8) of the human $\alpha 1$ (II) collagen chain. This sequence comes from published cDNA data (28). The site of the determined substitution of Cys-for-Arg ${ }_{519}$ is indicated. The boxed sequence shows peptide $T 4,6$. The letter $T$ and a vertical line show sites of cleavage by trypsin and peptides $T_{1}-T_{7}$ are identified above their respective sequences.

after disulfide cleavage (Fig. $5 a$, lanes 1 and 3). We believe this to be an abnormal $\alpha$ 1(II)-dimer from type II collagen molecules in which two mutant $\alpha$ (II) chains became disulfide bonded through their $\mathrm{Cys}_{519}$ residues. The mobility of the patient's $\alpha$ (II) chain was slightly slower than that of the control human $\alpha$ 1(II) chain (Fig. 5 a). Both $\alpha 1$ (II) and the normal $\beta$ component of the pepsin-solubilized type II collagen were radiolabeled by ${ }^{14} \mathrm{C}$-iodoacetate in proportion to their relative staining by Coomassie blue. This suggests that the cysteinecontaining $\alpha 1$ (II) chain was cross-linked by the aldehyde mechanism normally in the extracellular matrix.

The major CNBr-peptides from the patient's type II collagen also ran more slowly than their counterparts from control cartilage (Fig. $5 \mathrm{~b}$ ), which suggests from past experience a degree of posttranslational overmodification (18). Peptides CB10 and $\mathrm{CB} 11$, which lie respectively $\mathrm{COOH}$-terminal and $\mathrm{NH}_{2}$-terminal to the peptide $\alpha$ l(II)CB8 containing the mutation (19), were both affected. In contrast, amino acid substitutions for 


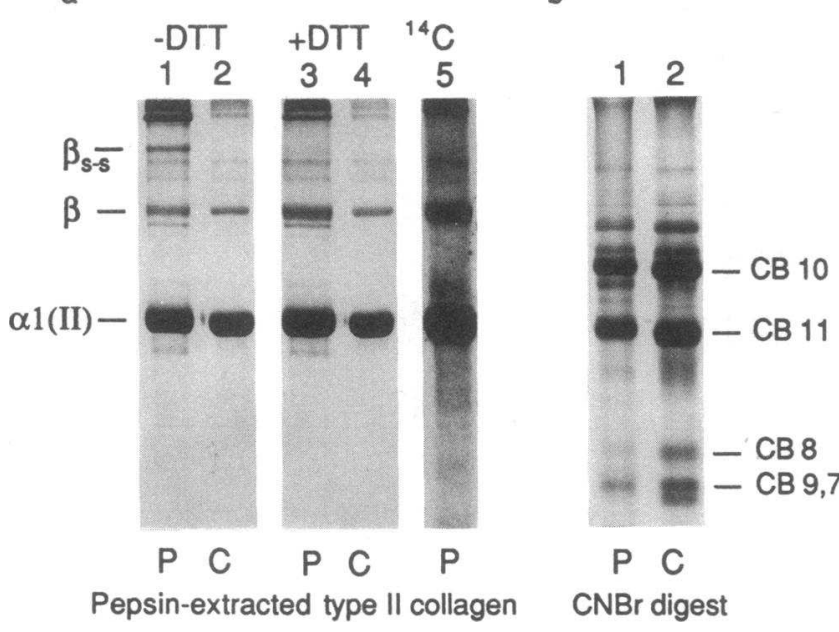

Figure 5. Electrophoretic properties of pepsin-solubilized mutant collagen, demonstrating the presence of an abnormal, disulfidebonded $\alpha 1$ (II)-dimer and evidence of posttranslational overmodification. (a) Pepsin-solubilized collagen from patient (lanes 1 and 3) and control human (lanes 2 and 4) cartilage, run without (lanes 1 and 2) and with (lanes 3 and 4) disulfide cleavage. All lanes except lane 5 were stained for protein with Coomassie blue. An additional protein band is seen in the patient's collagen ( $\beta$ s-s, lane 1 ), which disappeared on disulfide cleavage and is believed to be a cystine-bridged, intramolecular $\alpha 1$ (II)-dimer. The autoradiogram in lane 5 shows the ${ }^{14} \mathrm{C}$-activity incorporated into the patient's type II collagen by reduction and alkylation with ${ }^{14} \mathrm{C}$-iodoacetate. (b) Cyanogen bromide peptides prepared from type II collagen of patient (lane 1) and control (lane 2) cartilage. The mobilities of the major peptides CB8, CB10, and CB11 were slightly slower from the patient $\alpha 1$ (II) chain than from control human $\alpha$ l(II).

glycine in type I collagen identified in cases of osteogenesis imperfecta result in overmodification of only the portion of the collagen molecule that lies amino-terminal to the mutation site (20). Because during synthesis the direction of helix formation is believed to be in the $\mathrm{COOH}$-to- $\mathrm{NH}_{2}$ direction, these mutations are believed to hinder helix folding and so cause overmodification of the chains from the mutation site to the aminoterminus. In the present case, however, the cysteine is substituted for a $\mathrm{Y}$ position of the collagen (GXY) ${ }_{n}$ repeating sequence, which might affect triple-helix formation and molecular assembly differently than substitutions for glycine.

\section{Discussion}

The genomic mutation identified by Ala-Kokko et al. (10) is therefore expressed in the structural protein of the affected patient's articular cartilage. How does this amino acid substitution affect the properties of the extracellular collagen? For example, do the molecules become polymerized and cross-linked normally? The cysteine-containing $\alpha 1$ (II) chain was present in $\beta$-chains (presumably $\alpha 1$ (II) dimers linked by collagen's usual aldehyde-mediated mechanism), as evidenced by the radiolabeled, and hence cystine-containing $\beta$-component in lane 5 of Fig. $5 a$. In addition, the collagen content of pyridinoline residues (the mature cross-linking amino acids that provide the tensile strength of most skeletal tissue collagens) was in the normal range for human articular cartilage (21) (data not shown). This evidence for normal cross-linking and the insolubility of the patient's cartilage collagen in denaturing solvents lead us to conclude that collagen molecules containing the mutant $\alpha 1$ (II) chains were incorporated and covalently polymerized into extracellular fibrils. The content of mutant $\alpha 1$ (II) chains in the extracellular type II collagen was lower than the theoretical $50 \%$ for a dominant heterozygote; this might be explained if some molecules bearing mutant chains were selectively degraded at or soon after synthesis. Certain chain combinations may be more susceptible to degradation. (In theory for a homotrimer, seven-eighths of the molecules will contain mutant chains, one-eighth containing three, two-eighths containing two, and four-eighths containing one mutant chain: oneeighth molecules will be normal.) Other mutations of the human COL2A1 gene have been defined that have serious consequences, causing lethal or severe skeletal abnormalities in the clinical spectrum of the spondyloepiphyseal dysplasias (22-24).

We postulate that the presence of the mutant protein molecules in the extracellular collagen reduces the durability of the articular cartilage and manifests as the disorder, severe primary generalized OA. The fibrils may be less able in the long term to cope with the mechanical stresses that articular cartilage endures, perhaps through defects in material properties. In addition the collagen may be more susceptible to extracellular proteases that are active in matrix remodeling but which do not normally degrade the collagen triple-helix (25). The cysteine residue conceivably might serve as a covalent trap for matrix proteins that associate with the surface of collagen fibrils (26), with undesirable consequences. Because failure of the underlying collagen fabric of cartilage appears to be a key, irreversible event in the process of joint destruction in OA in all its subsets (27), defining how this single amino acid substitution is etiologically associated with severe but otherwise typical disease manifestations may prove instructive in understanding osteoarthritic joint failure.

\section{Acknowledgments}

The work was supported by National Institutes of Health grants AR37318 and AR20618.

\section{References}

1. Mankin, H. J., K. D. Brandt, and L. E. Shulman. 1986. Workshop on etiopathogenesis of osteoarthritis. Proceedings and recommendations. J. Rheumatol. 13:1130-1160.

2. Muir, I. H. M. 1980. The chemistry of the ground substance of joint cartilage. In The Joints and Synovial Fluid. L. Sokoloff, editor. Academic Press, Inc., New York. 27-94.

3. Eyre, D. R., J. J. Wu, and S. Apone. 1987. A growing family of collagens in articular cartilage: identification of five genetically distinct types. J. Rheumatol. 14:25-27.

4. Maroudas, A. 1982. Nutrition and metabolism of the intervertebral disk. In Symposium of Idiopathic Low Back Pain. A. A. White and S. L. Gordon, editors. C. V. Mosby Co., St. Louis, MO. 370-390.

5. Kellgren, J. H. 1964. The epidemiology of rheumatic diseases. Ann. Rheum. Dis. 23:109-122.

6. Rowatt Brown, A., and B. S. Rose. 1966. Familial precocious polyarticular osteoarthrosis of chondrodysplastic type. N. Z. Med. J. 65:449-461.

7. Palotie, A., P. Vaisanen, J. Ott, L. Ryhanen, K. Elima, M. Vikkula, K. Cheah, E. Vuorio, and L. Peltonen. 1989. Predisposition to familial osteoarthritis linked to type II collagen gene. Lancet. i:924-927.

8. Knowlton, R. G., P. L. Katzenstein, R. W. Moskowitz, E. J. Weaver, C. J. Malemud, M. N. Pathria, S. A. Jimenez, and D. J. Prockop. 1990. Genetic linkage of a polymorphism in the type II procollagen gene (COL2A1) to primary osteoarthritis associated with mild chondrodysplasia. N. Engl. J. Med. 322:526530. 
9. Katzenstein, P. L., C. J. Malemud, M. N. Pathria, J. R. Carter, R. P. Sheon, and R. W. Moskowitz. 1990. Early-onset primary osteoarthritis and mild chondrodysplasia. Radiographic and pathologic studies with an analysis of cartilage proteoglycans. Arth. Rheum. 33:674-684.

10. Ala-Kokko, L., C. T. Baldwin, R. W. Moskowitz, and D. J. Prockop. 1990. Single base mutation in the type II procollagen gene (COL2A1) as a cause of primary osteoarthritis associated with a mild chondrodysplasia. Proc. Natl. Acad. Sci. USA. 87:6565-6568.

11. Eyre, D. R., and H. Muir. 1975. The distribution of different molecular species of collagen in fibrous, elastic and hyaline cartilages of the pig. Biochem. $J$. 151:595-602.

12. Allen, G. 1981. Preliminary characterization of the protein. In Sequencing of Proteins and Peptides. T. S. Work and R. H. Burdon, editors. Elsevier Science Publishers B. V., Amsterdam. 30-31.

13. Bateman, J. F., T. Mascara, D. Chan, and W. G. Cole. 1986. Rapid fractionation of collagen chains and peptides by high performance liquid chromatography. Anal. Biochem. 154:338-344.

14. Eyre, D. R. 1987. Collagen cross-linking amino acids. Methods Enzymol. 144:115-139.

15. Miller, E. J. 1972. Structural studies on cartilage collagen employing limited cleavage and solubilization with pepsin. Biochemistry. 11:4903-4909.

16. Laemmli, U. K. 1970. Cleavage of structural proteins during the assembly of the head of bacteriophage T4. Nature (Lond.). 227:680-685.

17. Gross, E. 1967. The cyanogen bromide reaction. Methods Enzymol. 11:238-255.

18. Murray, L. W., J. Bautista, P. L. James, and D. L. Rimoin. 1989. Type II collagen defects in the chondrodysplasias. 1 . Spondyloepiphyseal dysplasias. Am. J. Hum. Genet. 45:5-15.

19. Miller, E. J., D. L. Woodall, and M. S. Vail. 1973. Biosynthesis of cartilage collagen: use of pulse labeling to order the cyanogen bromide peptides in the $\alpha 1$ (II) chain. J. Biol. Chem. 248:1666-1671.
20. Starman, B. J. D. R. Eyre, H. Charbonneau, M. Harrylock, M. A. Weis, L. Weiss, J. M. Graham, Jr., and P. H. Byers. 1989. Osteogenesis imperfecta: the position of substitution for glycine by cysteine in the triple helical domain of the proa I(I) chains of type I collagen determines the clinical phenotype. J. Clin. Invest. 84:1206-1214.

21. Eyre, D. R., T. J. Koob, and K. P. Van Ness. 1984. Quantitation of hydroxypyridinium crosslinks in collagen by high performance liquid chromatography. Anal. Biochem. 137:380-388.

22. Lee, B., H. Vissing, F. Ramirez, D. Rogers, and D. Rimoin. 1989. Identification of the molecular defect in a family with spondyloepiphyseal dysplasia. Science (Wash. DC). 244:978-980.

23. Vissing, H., M. D'Alessio, B. Lee, F. Ramirez, M. Godfrey, and D. Hollister. 1989. Glycine to serine substitution in the triple helical domain of proal(II) collagen results in a lethal perinatal form of short-limbed dwarfism. J. Biol. Chem. 264:18265-18267.

24. Tiller, G. E., D. L. Rimoin, L. W. Murray, and D. H. Cohn. 1990. Tandem duplication within a type II collagen gene (COL2A1) exon in an individual with spondyloepiphyseal dysplasia. Proc. Natl. Acad. Sci. USA. 87:3889-3893.

25. Gunja-Smith, Z., H. Nagase, and J. F. Woessner, Jr. 1989. Purification of the neutral proteoglycan-degrading metalloproteinase from human articular cartilage tissue and its identification as stromelysin matrix metalloproteinase-3. Biochem. J. 258:115-119.

26. Heinegard, D., and A. Oldberg. 1989. Structure and biology of cartilage and bone matrix noncollagenous macromolecules. FASEB (Fed. Am. Soc. Exp. Biol.) J. 3:2042-2051.

27. Maroudas, A. 1976. Balance between swelling pressure and collagen tension in normal and degenerate cartilage. Nature (Lond.). 260:808-809.

28. Baldwin, C. T., A. M. Reginato, C. Smith, S. A. Jiminez, and D. J. Prockop. 1989. Structure of cDNA clones coding for human type II procollagen. The $\alpha 1$ (II) chain is more similar to the $\alpha 1$ (I) chain that two other $\alpha$ chains of fibrillar collagens. Biochem. J. 262:521-528. 